\title{
HPLC Fingerprint Analysis and Content Determination of Extract with Anticancer Activities of Sedi linearis Herba
}

\author{
Diangang Liu' ${ }^{1}$, Qing Mei ${ }^{2}$, Weifang Long ${ }^{2}$, Xiangluan Wan ${ }^{1}$, Dingrong Wan ${ }^{2}$, Luyao Wang ${ }^{* 3}$
}

\section{Diangang Liu', Qing $\mathrm{Mei}^{2}$, Weifang Long ${ }^{2}$, Xiangluan Wan', Dingrong Wan', Luyao Wang*}

'Department of Pharmacy, Hubei Provincial Hospital of Traditional Chinese Medicine, Wuhan, CHINA. ${ }^{2}$ Department of Pharmacy, College of Pharmacy, South-Central University for Nationalities, Wuhan, CHINA.

${ }^{3}$ School of Chinese Medicine, Hong Kong Baptist University, Hong Kong, CHINA.

Correspondence

Luyao Wang

School of Chinese, Medicine, Hong Kong Baptist University, Hong Kong, CHINA.

Tel no: +852 52315540

E-mail: luyaoben@126.com (Luyao Wang)

History

- Submission Date: 17-08-2016;

- Review completed: 21-11-2016:

- Accepted Date: 20-12-2016.

DOI : 10.5530/pj.2017.2.22

Article Available online

http://www.phcogj.com/v9/i2

Copyright

(C) 2017 Phcog.Net. This is an openaccess article distributed under the terms of the Creative Commons Attribution 4.0 International license.

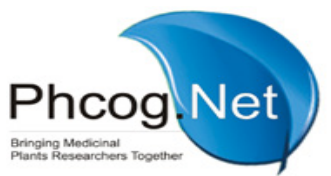

\begin{abstract}
Aims: The purpose of this paper was to develop a HPLC fingerprint analysis method, compare the chromatographic fingerprints characteristics of the ethyl acetate extract with anticancer activity from Sedi Linearis Herba (Sedum lineare Thumb.) collected in different seasons and environments, determine the contents of active ingredients hyperoside, isoquercetin and astragalin of each sample by HPLC, provide believable scientific foundations for quality control and evaluation of Sedi Linearis Herba. Methods: The analyte was analyzed using BDS Hypersil $\mathrm{C}_{18}$ as chromatographic column, acetonitrile $-0.1 \%$ acetic acid solution as the mobile phase (gradient elution). Results: The results showed that the major active ingredient contents of the samples collected in different seasons but at the same environment all had obvious differences. These ingredient contents of the samples collected in the end of April were much more than those in mid-August in general. Moreover, the major active ingredient contents of the samples picked in the same season but different environments were different too. For instance, the major ingredient contents of the sample in damp environment in August were more than those in sunny environment. Conclusion: All of these indicated that the HPLC fingerprint analysis and contents determination method established were very useful for quality analysis and control of Sedi Linearis Herba.
\end{abstract}

Key words: Sedum lineare Thunb., Anticancer Activity Ingredients, HPLC Fingerprint, Content Determination.

\section{INTRODUCTION}

The whole herb of Sedum line are Thumb. is a traditional ethnic drug in China named as Sedi Linearis Herba. It was widely used for the treatment of hepatitis, swollen sore throat, dysentery, dermatitis rhus, burn and scald, traumatic bleeding and so on. In particular, Sedi Linearis Herba has attracted attention due to its potential anticancer effect in Tujia minority area, western Hubei, China. ${ }^{1,2}$ The pharmacology researches had demonstrated that Sedi Linearis Herba possessed obvious effects of protecting liver, reducing alanine amino transferase (ALT) activity and eliminating jaundice on the mice with experimental acute liver injury. ${ }^{3}$ It also had an antioxidant effect and activities of decreasing MDA content in blood and hepatic tissue dramatically, and improving the superoxide dismutase. ${ }^{4}$ Research had also showed that its ethyl acetate extract had obvious anticancer effect on many cancer cells. ${ }^{5}$ Furthermore, Sedi Linearis Herba was always used as a vegetable in some regions of China. Thus, this drug deserved further research and development not only for its wide curative effects but also for its safety as a crude medicine.

It is well-known that the ingredients of crude medicine are complicated. And traditional quality control approaches on determination of any single active ingredient content may thus not be insufficient for a comprehensive assessment of crude medicine quality. The quality research results of many herbal medi- cines showed that HPLC fingerprint analysis of their active fractions could connect their qualities to the curative effects, and thus should be effective and appropriate for assessing the quality of herbal medicines. ${ }^{6-9}$ Our studies on the anticancer activity in vitro of different extract fractions of $S$. Lineare Thunb. have found that the ethyl acetate extract fraction and n-butyl alcohol extract fraction both had antitumor effects, and the activity of the former was better. ${ }^{5}$ This study developed a HPLC fingerprint analysis method, obtained and compared the chromatographic fingerprints of ethyl acetate fraction with anticancer activities extracted from $S$. lineare Thunb. samples picked in different seasons and environments, and determined the contents of hyperoside, isoquercetin and astragalin of each sample by HPLC. The three compounds determined all had anti-inflammatory activity. ${ }^{10-12}$ and isoquercetin could induce cell cycle block and apoptosis of human gastric carcinoma cells (SGC-7901)..$^{13}$ Hyperoside could inhibit growth of human lung cancer cells (A549), human colon cancer cells (HCT8), and human prostatic cancer cells (PC3), and possessed the hepatoprotective effect. ${ }^{11}$ So establishing the methods above and then obtaining the research results could provide reliable foundation for the quality evaluation and confirmation of the best harvest season of $S$. lineare Thunb.
Cite this article: Liu D, Mei Q, Long W, Wan X, Wan D, Wang L. HPLC Fingerprint Analysis and Content Determination of Extract with Anticancer Activities of Sedi Linearis Herba. Pharmacogn J. 2017;9(2):128-34. 


\section{SUBJECTS AND METHOD}

\section{Materials and reagents}

30 different batches of the samples were all collected in Hubei Province, China, shown in Table 1. And these samples were authenticated as S. lineare Thunb by Prof. Dingrong Wan, South Central University for Nationalities in China. All the samples were dried in drying oven at $60^{\circ} \mathrm{C}$ after being cleaned.

The chemical reference substances, hyperoside, isoquercetin and astragalin, were all purchased from National Institutes for Food and Drug Control in China. And the batch numbers were 111809-201102, 111521-201102, 20121255 respectively. The structures of these reference compounds were shown in Figure 1. HPLC-grade acetonitrile was purchased from Tedia Co., USA., the batch number is AS1122-001. The other reagents used were all of analytical grade.

\section{Instrumentation and chromatographic conditions}

Chromatography was performed with the Dionex Ultimate 3000 Series Chameleon data processing system (Dionex, USA). The analyte was analyzed using BDS Hypersil $\mathrm{C}_{18}\left(4.6 \mathrm{~m}^{\star} 250 \mathrm{~mm}, 5 \mu \mathrm{m}\right)$ as chromatographic column, and the column temperature was maintained at $30^{\circ} \mathrm{C}$. The injection volume was $10 \mu \mathrm{L}$. The mobile phase consisted of acetonitrile and $0.1 \%$ acetic acid. And the compounds were eluted at a flow rate of $1.0 \mathrm{ml} / \mathrm{min}$ in a gradient mode as follows: initially $5 \%$ acetonitrile changed to $15 \%$ of the ratio within $10 \mathrm{~min}$ and maintained for $10 \mathrm{~min}$, then continued to elute for $22 \mathrm{~min}$, increased to 19\% acetonitrile at $42 \mathrm{~min}$, and to $40 \%$ acetonitrile at $55 \mathrm{~min}$, again eluted for $10 \mathrm{~min}$, to $60 \%$ acetonitrile and followed by $10 \mathrm{~min}$ of column re-equilibration under the initial condition. Chromatograms were acquired at $265 \mathrm{~nm}$ with a UV detector.

\section{Preparation of sample solution}

The dried whole herb of S. Lineare Thunb. (about $1.0 \mathrm{~g}$ ) was powdered finely and sifted through 60-mesh sieve, accurately weighed, and then extracted by ultrasonic for $60 \mathrm{~min}$ in an erlenmeyer flask with $50 \mathrm{ml}$ of $70 \%$ alcohol solution (V/V). The extract was filtered after being cooled, and Erlenmeyer flask was rinsed twice with $15 \mathrm{ml}$ of $70 \%$ alcohol each time. The filtrates were mixed, and dried by rotary evaporators. The extracts above were dissolved with $15 \mathrm{ml}$ of distilled water and then extracted three times with $15 \mathrm{ml}$ of ethyl acetate each time by separating funnel. The extracts were-mixed, dried by rotary evaporator, and dissolved with a small amount of methanol. The methanol solution was removed thoroughly into a $10 \mathrm{ml}$ volumetric flask and diluted to $10 \mathrm{ml}$ with methanol, shook up, and filtered through a $0.45 \mu \mathrm{m}$ micropore filter membrane into a HPLC vial prior to analysis.

\section{Preparation of mixed reference solution}

The mixed standard solution of hyperoside $\left(0.1 \mathrm{mg} \cdot \mathrm{mL}^{-1}\right)$, isoquercetin $\left(0.2 \mathrm{mg} \cdot \mathrm{mL}^{-1}\right)$ and astragalin $\left(0.15 \mathrm{mg} \cdot \mathrm{mL}^{-1}\right)$ was prepared by dissolving the dried reference substances of hyperoside, isoquercetin and astragalin into methanol accurately.

\section{Similarity evaluation of HPLC fingerprint}

The fingerprints data of each 10 batches ethyl acetate fraction extracted from one of three types of S. lineare Thunb. harvested at sunny environment in the end of April and the middle of August, or damp environment in the middle of August were imported respectively into a professional software named "Similarity evaluation system for chromatographic fingerprint of Traditional Chinese Medicine (Version 2004 A)", which was recommended by State Food and Drug Administration of China (SFDA). The system can compare these data automatically and then give out the standard fingerprints and common peaks of three types of S. lineare Thunb. Harvested in the different seasons and environments. And an overall similarity evaluation on the fingerprints of different batches of samples with their standard fingerprints was made.

\section{Quantitation of 3 compounds in Sedum lineare Thunb.}

Since the resolution value between the detected compound peaks and the adjacent ones were larger than 1.5, the chromatographic system would be further used for quantitative analysis. All the peak areas of hyperoside, isoquercetin and astragalin in the chromatograms of the different samples obtained in the "HPLC Fingerprint Analysis" experiment part were recorded. And their contents were all calculated according to their linear regression equations separately.

\section{RESULTS}

\section{HPLC fingerprint analysis}

To perform HPLC fingerprint analysis, the chromatograms of 30 batches of the samples have to be standardized. The processes of standardization included selection of "common peaks" in chromatograms and normalization of retention times of all the common peaks. So in this assay part, 10 batches of ethyl acetate extracts of each $S$. lineare Thunb. sample harvested at sunny environment in April and August, and damp environment in August were analyzed respectively with the developed procedures to standardize their fingerprints.

The HPLC fingerprints common models of three types of Sedum lineare Thunb. samples from various locations in different seasons were established and shown in Figure 2. Similarity analysis was performed by comparing each types of the individual sample chromatograms with their reference chromatogram (the fingerprints common models) via the Chromatographic Fingerprint Similarity Evaluation software published by SFDA. And the results showed that their similarities were all more than 0.995 , which met the fingerprint requirements.

The peaks existing in all 10 batches of samples were assigned as "common peaks" for one type of $S$. lineare Thunb. 16 common peaks were found in the chromatogram of Sedum lineare Thunb. harvested at sunny environment in the end of April, and 15 common peaks were found in both chromatograms of samples harvested in sunny and damp environments in the middle of August (Figure 3). Peak 8, which was defined as isoquercitin, was taken as the reference peak for its stability and larger relative peak area. Besides, the relative retention time (RRT), which was related to the reference peak of each chromatogram, was calculated for similarity analysis. The average relative retention times of each common peak of 30 samples were $0.205,0.331,0.463,0.689,0.711,0.847,0.953,1.000$, $1.043,1.188,1.357,1.447,1.511,1.637,1.733$, and 2.259 respectively (denoted from 1 to 16 ).

\section{Identification of some peaks}

Peak 7, 8 and 11 in the chromatograms were identified to be hyperoside, isoquercetin and astragalin respectively, by comparing with the chromatogram of the mixed reference solution (Figure 4).

\section{HPLC method validation}

The reliability of the HPLC method established in this paper was proved by checking its linearity, precision, repeatability, stability and recovery.

\section{Linearity}

To get the linear regression equations of hyperoside, isoquercetin and astragalin, five levels of mixed reference solutions were made by diluting the stock mixed reference solution respectively. The concentrations of hyperoside were $0.8,2.0,4.0,8.0,12.0 \mu \mathrm{g} / \mathrm{ml}$, those of isoquercetin were $10,25,50,100,150 \mu \mathrm{g} / \mathrm{ml}$, and those of astragalin were $6,15,30,60,90 \mu \mathrm{g} / \mathrm{ml}$ respectively. The chromatographic peak areas values of the three marker 
<smiles>[3H]c1cc(C2=C(C[C@H]3C[C@H](CF)[C@@H](F)[C@H](F)[C@H]3C)C(=C)c3c([Hg])cc(F)cc3C2)ccc1[12F]</smiles>

Hyperoside

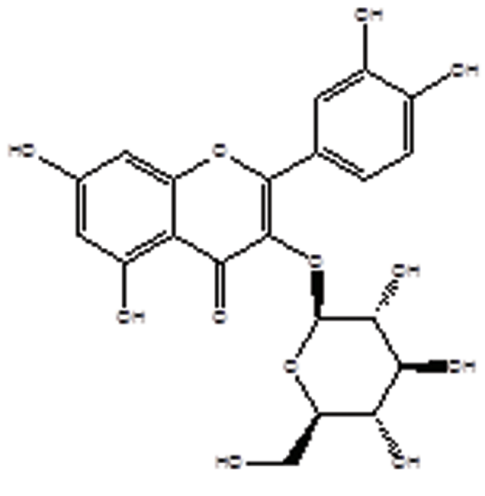

Isoquercetin

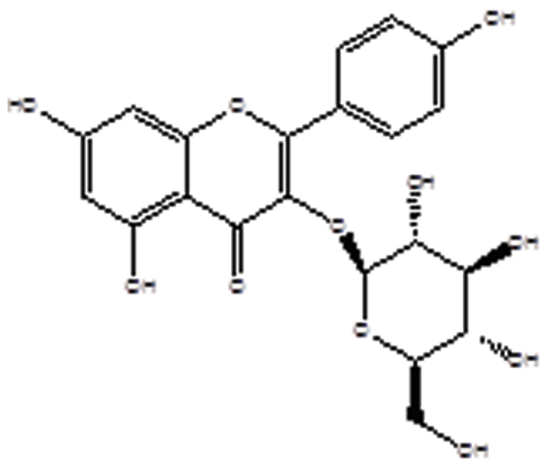

Astragalin

Figure 1: Chemical structures of hyperoside, isoquercetin and astragalin.
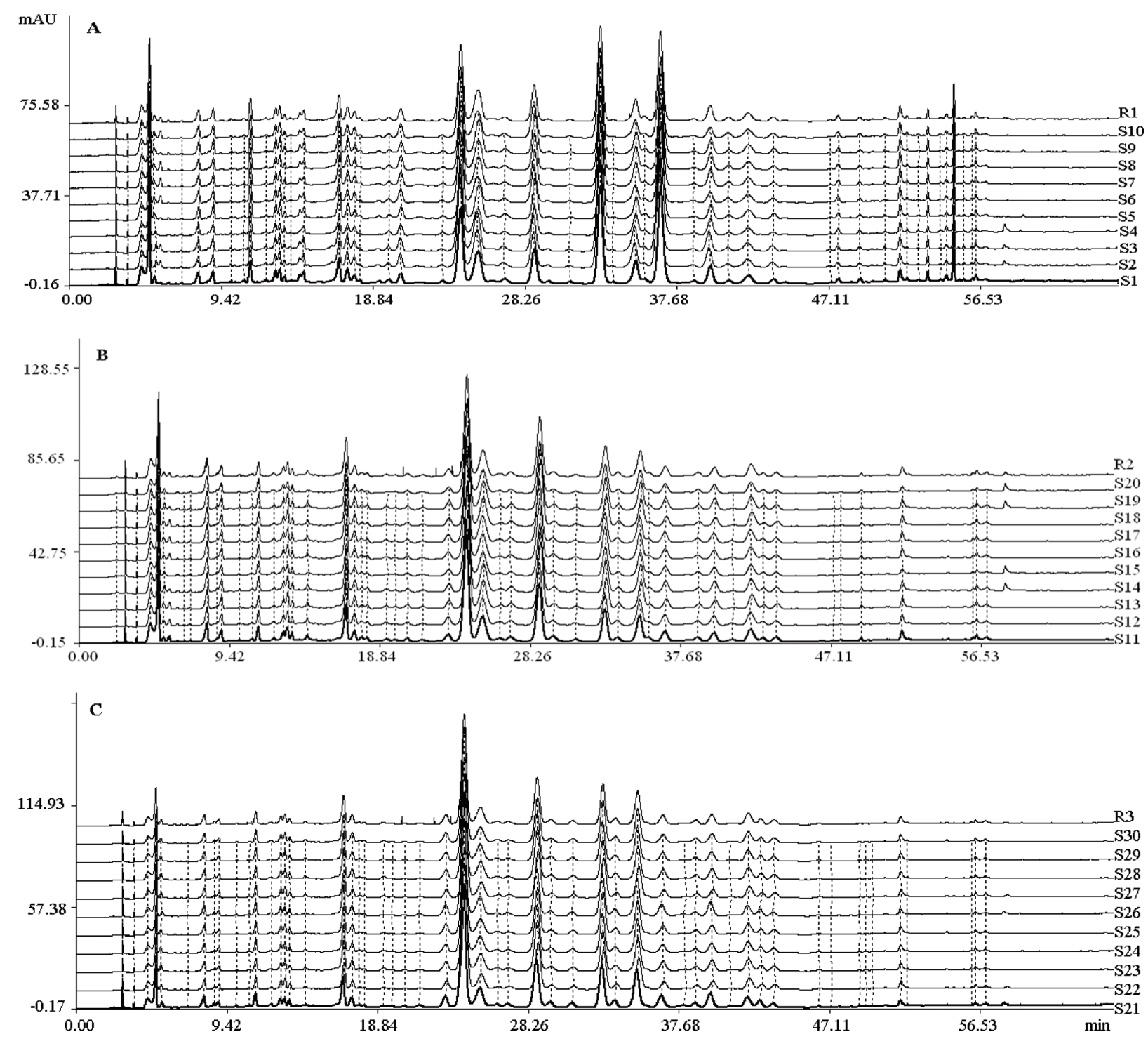

Figure 2: HPLC fingerprints common models of the ethyl acetate extracts of Sedum lineare Thunb. from various locations in different seasons. A. S1-S10: 10 batches of the samples harvested at sunny environment in the end of April; B. S11-S20: 10 batches of the samples harvested at sunny environment in the middle of August; C. S21-S30: 10 batches of the samples harvested at damp environment in the middle of August, R1-R3: HPLC reference chromatograms of the samples harvested at sunny environment in April, at sunny and damp environment in August. 

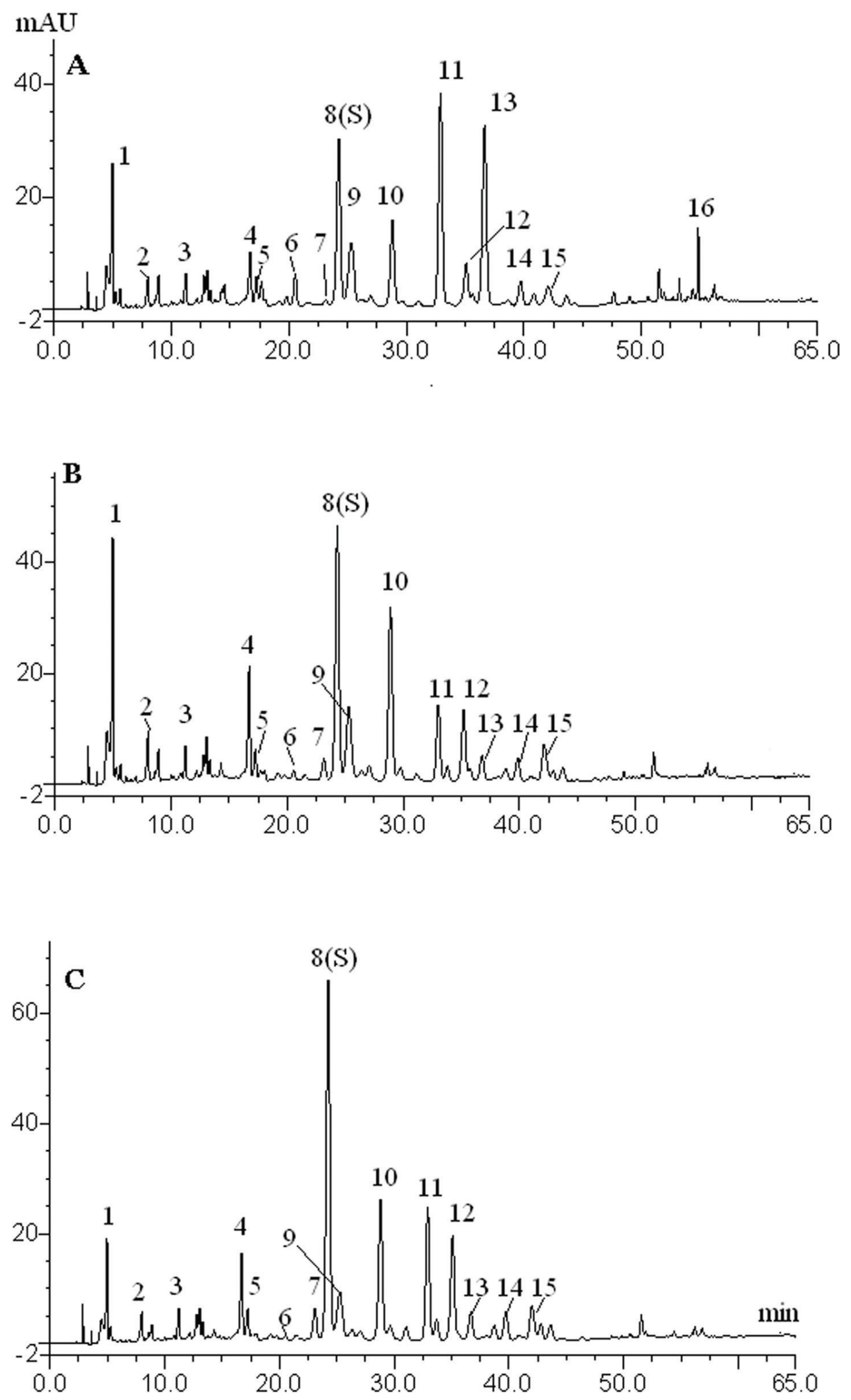

Figure 3: HPLC fingerprints and the common peaks of the ethyl acetate extracts of S. Lineare Thunb. harvested from various locations in different seasons. A. Harvested at sunny environment in April; B. Harvested at sunny environment in August; C. Harvested at damp environment in August. 


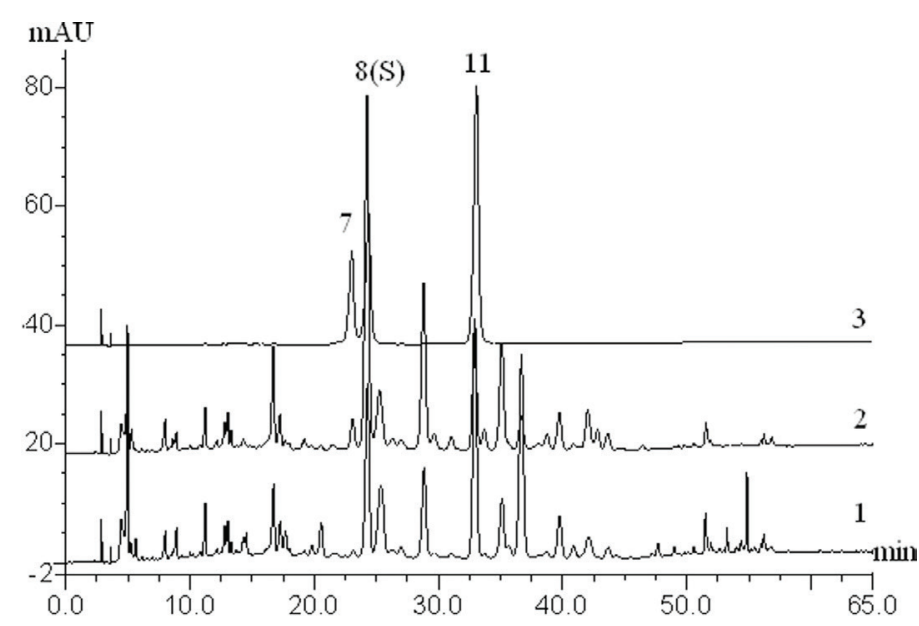

Figure 4: Definition of the three common peaks in the HPLC fingerprints of the ethyl acetate extracts of Sedum lineare Thunb. Peaks: 7, hyperoside; 8 (S), isoquercetin; 11, astragalin. (1. Harvested at sunny environment in April; 2. Harvested at damp environment in August; 3. Mixed reference solution.)

compounds were used as $\mathrm{Y}$ axis and their concentrations as $\mathrm{X}$ axis, then the linear regression equations were obtained as $\mathrm{Y}=0.282 \mathrm{X}-0.0037$, $\mathrm{r}=0.9995$ (hyperoside), $\mathrm{Y}=0.315 \mathrm{X}-0.6170, \mathrm{r}=0.9996$ (isoquercetin), and $\mathrm{Y}=0.284 \mathrm{X}-0.5229, \mathrm{r}=0.9999$ (astragalin). The high correlation coefficients of three standard curves indicated fine linearity between the concentrations of three marked compounds and their peak areas in the range of $0.8 \sim 12 \mu \mathrm{g} / \mathrm{ml}$ (hyperoside), 10 150 $\mu \mathrm{g} / \mathrm{ml}$ (isoquercetin), and $6 \sim 90 \mu \mathrm{g} / \mathrm{ml}$ (astragalin) separately.

\section{Precision}

The sample No. 1 solution was analyzed five times continuously by HPLC under the chromatographic conditions above. The relative standard deviation (RSD) values of the relative retention times (RRT) of the common peaks in each chromatogram were calculated. It was found that the RSD values of RRT were all less than $0.10 \%$ and those of their relative peak areas (RPA) were all less than $1.81 \%$, suggesting that the method used had a high precision.

\section{Repeatability}

Five sets of the sample No. 1 powders were taken, treated according to the "sample solution preparation" method above, and analyzed respectively by HPLC, and then their fingerprints were obtained. The RSD values of the relative retention times and the relative peak areas of each common peak were calculated. They were less than $0.10 \%$ and $3.88 \%$ respectively, indicating that this method had a good repeatability.

\section{Stability}

The sample No. 1 was analyzed by HPLC at $0,2,4,8$, and 12 hours after sample solution preparation. The RSD values of the relative retention times and the relative peak areas of each common peak were $0.59 \%$ and $3.48 \%$ respectively. This showed that the test solution was stable in 12 hours.

\section{Recovery and Accuracy}

The accuracy could be evaluated by calculating the recovery after a standard addition procedure. In this study, $2 \mathrm{ml}$ of five ethyl acetate test solutions (No. 26) were added with a certain amount of hyperoside, isoquercetin and astragalin respectively before HPLC determination. The recovery and the RSD values were presented in Table 2 . The results showed that the HPLC method established above was accurate and could be used in the content determination of hyperoside, isoquercetin and astragalin in S. lineare Thunb. samples.

\section{Table 1: Sources of Sedum lineare Thunb. samples}

\begin{tabular}{ccc}
\hline No. & Origin & Harvest Date \\
\hline $1-10$ & Sunny environment, Huangmei, Hubei & 30, April, 2012 \\
$11-20$ & Sunny environment, Huangmei, Hubei & 12, August, 2012 \\
$21-30$ & Damp environment, Huangmei, Hubei & 12,August, 2012 \\
\hline
\end{tabular}

Table 2: Recoveries of Hyperoside, Isoquercetin and Astragalin

\begin{tabular}{|c|c|c|c|c|c|c|c|}
\hline & 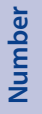 & $\begin{array}{l}\text { Content in } \\
\text { sample }(\mu \mathrm{g})\end{array}$ & $\begin{array}{c}\text { Content } \\
\text { added }(\mu \mathrm{g})\end{array}$ & $\begin{array}{c}\text { Amount } \\
\text { determined }(\mu \mathrm{g})\end{array}$ & Recovery (\%) & $\begin{array}{l}\text { Mean of the } \\
\text { recovery (\%) }\end{array}$ & $\begin{array}{l}\text { RSD } \\
(\%)\end{array}$ \\
\hline \multirow{5}{*}{ 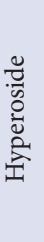 } & 1 & 9.5 & 9.5 & 19.1 & 101.05 & \multirow{5}{*}{102.95} & \multirow{5}{*}{1.65} \\
\hline & 2 & 9.5 & 9.5 & 19.2 & 102.11 & & \\
\hline & 3 & 9.5 & 9.5 & 18.9 & 98.95 & & \\
\hline & 4 & 9.5 & 9.5 & 19.3 & 103.16 & & \\
\hline & 5 & 9.5 & 9.5 & 19.0 & 100.00 & & \\
\hline \multirow{5}{*}{ 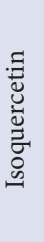 } & 1 & 125.7 & 128.0 & 256.0 & 101.80 & \multirow{5}{*}{100.88} & \multirow{5}{*}{1.97} \\
\hline & 2 & 125.7 & 128.0 & 257.6 & 103.05 & & \\
\hline & 3 & 125.7 & 128.0 & 256.1 & 101.88 & & \\
\hline & 4 & 125.7 & 128.0 & 253.0 & 99.45 & & \\
\hline & 5 & 125.7 & 128.0 & 251.4 & 98.20 & & \\
\hline \multirow{5}{*}{ 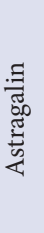 } & 1 & 43.7 & 47.1 & 92.4 & 103.40 & \multirow{5}{*}{101.66} & \multirow{5}{*}{1.67} \\
\hline & 2 & 43.7 & 47.1 & 92.1 & 102.76 & & \\
\hline & 3 & 43.7 & 47.1 & 91.9 & 102.34 & & \\
\hline & 4 & 43.7 & 47.1 & 91.0 & 100.42 & & \\
\hline & 5 & 43.7 & 47.1 & 90.5 & 99.36 & & \\
\hline
\end{tabular}




\section{Quantitation of 3 compounds in Sedum lineare Thunb}

As hyperoside and isoquercetin showed good anticancer activities while astragalin possessed certain anti-inflammatory activity, the contents of these three compounds in 30 samples were calculated simultaneously by taking their peak areas into the corresponding linear regression equations respectively. The content ranges of hyperoside, isoquercetin and astragalin in the 10 samples harvested at sunny environment in the end of April were 0.34 0.46 mg/g, 10.38 12.82 mg/g, and 14.52 17.42 mg/g respectively. While the contents of hyperoside and isoquercetin of the 10 samples harvested at sunny environment in the middle of August were higher with the ranges of $1.28 \sim 1.68 \mathrm{mg} / \mathrm{g}$ and $18.20 \sim 21.91 \mathrm{mg} / \mathrm{g}$ respectively. Nevertheless, the content of astragalin was lower with the range of $6.97 \sim 7.78 \mathrm{mg} / \mathrm{g}$. For the 10 samples harvested at damp environment in the middle of August, the contents of three compounds were all higher than those grown in sunny environment in August. In details, the contents of hyperoside ranged from 2.09 to $2.79 \mathrm{mg} / \mathrm{g}$, isoquercetin content ranged in $25.96 \sim 31.52 \mathrm{mg} / \mathrm{g}$, and astragalin content was in the range of $11.10 \sim 12.24 \mathrm{mg} / \mathrm{g}$.

\section{DISCUSSION}

\section{HPLC fingerprint analysis}

Comparing the chromatograms of both $S$. lineare Thunb. samples harvested at sunny environment in April and August (Figure 3-A and B), it could be found that the number of their common peaks was different. The peak 16 only existed in the samples harvested in April. The areas of common peaks were also different. For instance, the average areas of peak $1,4,7,8$ and 10 in the chromatograms of samples harvested in the middle of August were bigger than those collected in the end of April, indicating that the contents of those compounds in the samples of August were higher. On the contrary, the average areas of peak 11 and 13 in the chromatograms of samples harvested in the end of April were bigger than those of samples in the middle of August. So the contents of the compounds corresponding with peak 11 and 13 in samples of April should be higher. In general, the area of the total common peaks in the fingerprints of samples harvested in April was much bigger than that in August (took the mean of 10 batches of the samples). Lots of ingredients in plant medicines usually cure diseases together by complex synergy, they should be studied by considering all active ingredients. Combined with our earlier findings, ${ }^{5}$ it was further confirmed that the best harvest time of S. Lineare Thunb. Should be the flower season from the end of April to early May.

In a similar way, the fingerprints of the samples collected in August at sunny and damp environments were compared Figure 3-B and C). The results showed that the number of their common peaks was both 15 , but the areas were different. For example, the average areas of peak 8, 11 and 12 in the chromatograms of the samples harvested at damp environment were bigger than those of the samples grown at sunny environment. Meanwhile, the average areas of peak 1 and 10 in the chromatograms of the samples harvested at sunny environment were bigger than those of the samples of damp environment. In general, the area of the total common peaks in the fingerprints of the samples of damp environment was much bigger than that of sunny environment, indicating that the quality of $S$. lineare Thunb. growing at damp environment was better than that at sunny environment.

\section{Quantitation of 3 compounds in Sedum lineare Thunb}

As the experimental data shown, the contents of hyperoside in all the samples were very low, and its content in the samples of damp environment in August was the highest. The isoquercetin content in 30 samples were all very high and that in the samples of damp environment in August was also the highest. For astragalin, the content of samples in April at sunny environment was the highest.

\section{CONCLUSION}

A HPLC method, including fingerprints analysis of the ethyl acetate extracts of S. lineare Thunb. samples harvested in different seasons from different habitats, and quantitation on two anticancer active compounds and one anti-inflammatory compound, has been developed in this paper. The method provided reliable references for evaluating its quality. The results showed that the major ingredient contents of the samples collected in the end of April were much more than those in mid-August in general, and the major ingredient contents of the sample in damp environment in August were more than those in sunny environment. Therefore, the best harvest season of $S$. lineare Thunb. should be the flower season from the end of April to the early May. Moreover, the quality of the samples in August grown at damp environment was better than those at sunny environment. Our previous studies on the anticancer activities in vitro of different extract fractions of Sedi Linearis Herba have found that both the ethyl acetate and n-butyl alcohol fractions had anticancer effects, and the activity of the former was better. The ingredients extracted by ethyl acetate had good solubility in hot water, and the water always as the solvent for TCM decocting process. Therefore, the analysis of the ethyl acetate extract fraction could effectively evaluate the quality of this crude drug.

\section{ACKNOWLEDGEMENT}

The author gratefully acknowledges the financial support by the Collaborative Innovation Center of Hubei Province for New Geriatric TCM Products to the Research.

\section{CONFLICTS OF INTEREST}

All contributing authors declare no conflicts of interest.

\section{ABBREVIATIONS USED}

ALT: Alanine amino transferase, MDA: Malondialdehyde, HPLC: High performance liquid chromatography, SFDA: State Food and Drug Administration of China, RSD: Relative standard deviation, RRT: Relative retention time, RPA: Relative peak areas.

\section{REFERENCES}

1. Pharmacopoeia Commission of People's Republic of China. Pharmacopoeia of People's Republic of China (1977), Volume I. People's Medical Publishing House 1978;297.

2. Wan DR. A survey of "Chuipencao" and the other ethno medicines from the same genus (Sedum L.). Lishizhen Medicine and Materia Medica Research. 2007;18(8):1853-5.

3. Zhou Q, Liu JX, Zhou L, Xiong XQ, Zhao HY. Protective effects of Sedum lineare Thunb. on experimental acute hepatic injury in mice. Lishizhen Medicine and Materia Medica Research. 2005;16(12):1228.

4. Zhou Q, Xu QL, Zhou L, Lian QS, Zhang XY, Zeng AP, Liu JX. The effects of Sedum lineare Thunb. on anti-lipid peroxidation induced by $\mathrm{CCl} 4$ in mice. Journal of Gannan Medical University. 2003;23(2):128-30.

5. Chen YJ, Lin QX, Wan DR, Zhao XP, Hu J. Study on the anti-tumor activities of different extract fractions and the total flavones of the three Sedum plant drugs. Journal of Minzu University of China (Natural Sciences Edition). 2011;20(5):8892.

6. Yan SK, Zhang WD, Liu RH, Zhan YC. Chemical fingerprinting of Shexiang Baoxin Pill and simultaneous determinaton of its major constituents by HPLC with evaporative light scattering detection and electrospray mass spectrometric detection. Chemical and Pharmaceutical Bulletin. 2006;54(7):1058-62. http:// dx.doi.org/10.1248/cpb.54.1058; PMid:16819233.

7. Zou $P$, Hong $Y$, Koh HL. Chemical fingerprinting of Isatis indigotica root by RP-HPLC and hierarchical clustering analysis. Journal of Pharmaceutical and Biomedical Analysis. 2005;38(3):514-20. http://dx.doi.org/10.1016/j.jpba.2005. 01.022; PMid:15925253.

8. Islam MN, Lee SK, Jeong SY, Kim DH, Jin CB, Yoo HH. Quantitative and pattern 
recognition analysis for the quality evaluation of Herba Epimedii by HPLC. Bulletin of the Korean Chemical Society. 2009;30(1):137-44. http://dx.doi. org/10.5012/bkcs.2009.30.1.137

9. Qian GS, Leung SY, Lu GH, Leung KS-Y. Differentiation of Rhizoma et Radix Polygoni Cuspidati from closely related herbs by HPLC fingerprinting. Chemical and Pharmaceutical Bulletin. 2006;54(8):1179-86. http://dx.doi.org/10.1248/ cpb.54.1179; PMid:16880665.

10. Fernandez J, Reyesb R, Ponce H, Oropeza M, Van Calsteren MR, Jankowski C, Campos MG. Isoquercitrin from Argemone Platyceras inhibits carbachol and leukotriene D4-induced contraction in guinea-pig airways. European Journal of Pharmacology. 2005;522(1):108-15 http://dx.doi.org/10.1016/j. ejphar.2005.08.046; PMid:16202993.

11. Lin $\mathrm{P}, \mathrm{Yi}$ HW, Zhang F. Research on the pharmacology of hyperoside. Modern Chinese Medicine. 2012;14(10):23-6

12. Soromou LW, Chen N, Jiang L, Huo MX, Wei MM, Chu X, et al. Astragalin attenuates lipopolysaccharide induced inflammatory responses by down regulating NF-kB signaling pathway. Biochemical and Biophysical Research Communications. 2012:419(2):256-61 http://dx.doi.org/10.1016/s. bbrc.2012.02.005; PMid:22342978.

13. Li YY, Zhao SJ, Bai CZ, Zhang LW, Wang ZH. Effect of isoquercetin from Fagopyrum tataricum on the proliferation and apoptosis of human gastric carcinoma cell line SGC-7901. Food Science. 2013;35(3):193-19.

\section{PICTORIAL ABSTRACT}

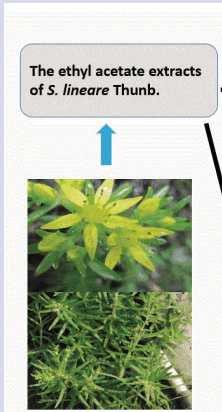

Sedum lineare Thunb.
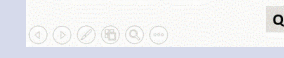

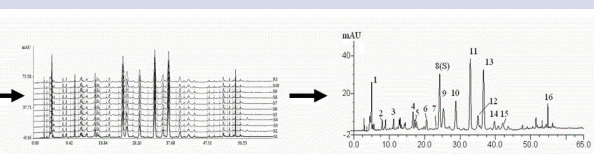

HPLC fingerprints analysis

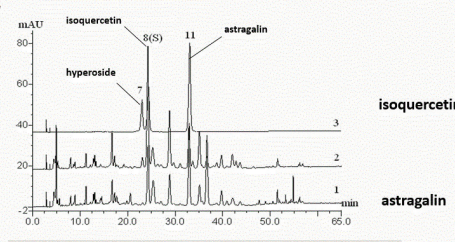

Quantitation of hyperoside, isoquercetin and astragalin

\section{SUMMARY}

A HPLC method, including fingerprints analysis of the ethyl acetate extracts of $S$. lineare Thunb. samples harvested in different seasons from different habitats, and quantitation on two anticancer active compounds and one anti-inflammatory compound, has been developed in this paper.

The best harvest season of S. Lineare Thunb. should be the flower season from the end of April to the early May. Moreover, the quality of the samples in August grown at damp environment was better than those at sunny environment.

All of the results indicated that the HPLC fingerprint analysis and contents determination method established were very useful for quality analysis and control of Sedi Linearis Herba.

\section{ABOUT AUTHORS}

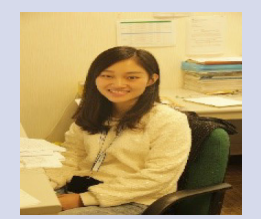

Wand Luyao: She is a research assistant (doctoral student) at the Hong Kong Baptist University (HKBU). She is the certification expert of ISO/TC249 (International Organization for Standardization, Traditional Chinese Medicine), the member of China Association for Standardization (CAS), the member of the Institute for Advancing Translational Medicine in Bone \& Joint Diseases. Has research experiences on identification, quality analysis, antitumor activity and anti-metastasis evaluation of Traditional Chinese Medicines.

Cite this article: Liu D, Mei Q, Long W, Wan X, Wan D, Wang L. HPLC Fingerprint Analysis and Content Determination of Extract with Anticancer Activities of Sedi Linearis Herba. Pharmacogn J. 2017;9(2):128-34. 